16

\title{
Поляризационные эффекты и резонансное поглощение при дифракции терагерцовых волн на графеновых метаповерхностях
}

\author{
(C) А.М. Лерер ${ }^{1}$, Г.С. Макеева ${ }^{2}$ \\ ${ }^{1}$ Южный федеральный университет, фризический фракультет, \\ 344090 Ростов-на-Дону, Россия \\ ${ }^{2}$ Пензенский государственный университет, \\ 440026 Пенза, Россия \\ e-mail: lerer@sfedu.ru
}

Поступила в редакцию 29.08.2018 г.

\begin{abstract}
Тремя электродинамическими методами решена задача дифракции электромагнитных волн на графеновых метаповерхностях $-2 D$-периодических решетках прямоугольных графеновых нанолент, расположенных на подложках, содержащих диэлектрические и графеновые слои. Исследованы зависимости от частоты коэффициента прохождения через $\mathrm{THz}$ поляризаторы на основе графеновых метаповерхностей при изменении угла ориентации векторов падающей ТЕМ-волны к нанолентам графена для различных значений химического потенциала. Показано, что на частотах резонанса поверхностного плазмон-поляритона графеновые метаповерхности на многослойных подложках являются электрически управляемыми поглотителями почти $100 \%$ падающей на них энергии в $\mathrm{THz}$ диапазоне частот.
\end{abstract}

DOI: $10.21883 /$ OS.2018.12.46948.257-18

Уникальные оптические и электронные свойства графена открыли новые горизонты для фундаментальной физики и технологических достижений в электронике, оптике и энергетике. Графен имеет существенные преимущества, такие как почти не зависящее от длины волны поглощение, управляемость посредством электростатического легирования, высокая концентрация носителей заряда, низкая скорость диссипации, экстраординарные электронные свойств и возможность ограничивать электромагнитную энергию в беспрецедентно малых объемах.

В последнее десятилетие прогресс в изготовлении графена и наноструктур на основе графена открывает большие возможности для создания перестраиваемых $\mathrm{THz}$ и ИК метаматериалов и управляемых интегральных плазмонных устройств и метаматериалов для потенциальных применений в устройствах $\mathrm{THz}$ и ИК диапазонов [1].

Использование фигурного графена представляется чрезвычайно интересным для преодоления ограничений существующих технологий с точки зрения рабочих частот, сложности электрического смещения благодаря известному эффекту управляемости графена электрическим полем, а также интеграции и миниатюризации $[2,3]$. В последние годы наблюдается значительный прогресс в развитии технологии получения графеновых нанолент [4]. Новые направления, новые перспективы и новые приложения появляются в области метаматериалов на основе графена и их 2D-версии, метаповерхностей, ультратонких структур.

Разработка и изготовление $\mathrm{THz}$ и ИК устройств на основе графена зависят от развития средств моделиро- вания на основе точных и адекватных математических моделей, базирующихся на строгом решении уравнений Максвелла совместно с моделью проводимости графена.

В графеновом слое, расположенном на поверхности диэлектрического слоя в ТГц диапазоне, может распространяться поверхностный плазмон-поляритон (ППП). В ограниченном графеновом элементе наблюдается резонанс ППП, при котором резко возрастают плотность энергии вблизи слоя, плотность тока и потери. Из-за большого коэффициента замедления ППП резонансные размеры этого элемента много меньше длины волны в вакууме. Этот эффект используется в ряде $\mathrm{THz}$ устройств, в том числе поглощающих метаповерхностях [5-12]. Обычно они являются однопериодическими структурами, образованными графеновыми лентами, и содержат поглощающие слои, например металлические пленки. Аналогичные устройства, содержащие плазмонные материалы, используются и в оптическом диапазоне [13-16]. Роль поглощающих слоев очевидна. Периодические элементы и диэлектрические слои, на которые нанесены эти элементы, обеспечивают согласование, т. е. минимизацию отражения при резонансе, а в некоторых структурах и дополнительные потери. Выбор размеров и параметров элементов позволяет получить резонанс в заданном частотном диапазоне. Применение графеновых элементов позволяет добиться резонанса в $\mathrm{THz}$ диапазоне. Кроме того, в графеновых структурах положение резонанса поглощения можно изменять внешним электрическим полем.

Целью работы является исследование взаимодействия электромагнитных волн с графеновыми метаповерхностями с помощью математического моделирования, ба- 
зирующегося на строгом решении краевых задач для уравнений Максвелла, и прогнозирование физических эффектов для разработки перспективных перестраиваемых устройств на основе графеновых метаповерхностей в $\mathrm{THz}$ диапазоне частот.

\section{1. Математические модели}

Рассмотрим 3D-задачу дифракции электромагнитной волны на графеновой метаповерхности, состоящей из прямоугольных графеновых полосок (нанолент графена конечной длины) (рис. 1, $a$ ), расположенных на многослойной подложке, содержащей графеновые и диэлектрические слои (рис. $1, b$ ), в ТГц диапазоне частот. Полоски с размерами $w, l$, где $w$ - ширина и $l$ - длина наноленты, периодичность 2D решетки $a, b$ по оси $x$ и $y$ соответственно (рис. $1, b$ ).

Пусть на графеновую метаповерхность падает плоская однородная электромагнитная волна с волновым вектором $\mathbf{k}$ и частотой $\omega$. Волна распространяется вдоль оси $z$, вектор напряженности электрического поля $\mathbf{E}$ ТЕМ-волны ориентирован под углом $\varphi$ к нанолентам графена, вектор $\mathbf{k}$ ориентирован под углом падения $\theta$ к нормали к плоскости нанолент графена (рис. 1,b).

Монослой графена характеризуется поверхностной проводимостью $\sigma$, определяемой формулой Кубо [17]. Проводимость графена, согласно модели Кубо, зависит, в частности, от химического потенциала, который можно изменять, например, приложенным внешним электрическим полем [17].

В электродинамической модели $\mathrm{THz}$ поляризаторов краевую 3D-задачу дифракции для уравнений Максвелла с соответствующими электродинамическими граничными условиями на периодической 2D-структуре решаем на основе декомпозиционного подхода [18]. Элементарную ячейку периодической 2D-структуры (рис. 1,a), содержащую отрезок канала Флоке с неоднородным заполнением в виде прямоугольной наноленты графена конечной длины и диэлектрического слоя (рис. 1,b), будем рассматривать как автономный блок с каналами Флоке (ФАБ) [19].

Вычислительный алгоритм определения дескрипторов (матриц проводимости) ФАБ, содержащего прямоугольную наноленту графена конечной длины (рис. 1, $b$ ), построен на основе решения краевой 3D-задачи дифракции проекционным методом Галеркина [20].

При расчете поглотителей используются два более специализированных метода. В первом методе графеновые слои, как обычно, заменяются бесконечно тонкими импедансными слоями, импеданс которых определяется формулой Кубо. В этом приближении задача сводится к решению парных сумматорных уравнений относительно плотности тока на полосках [21]. Эти уравнения решены методом Галеркина, в котором базисные функции полиномы Гегенбауэра.
Второй метод основан на численно-аналитическом методе решения объемного интегродифференциального уравнения (ОИДУ) для диэлектрических тел [22]. Неизвестными в ОИДУ являются компоненты напряженности электрического поля внутри диэлектрических полосок. Для интеграции графеновых слоев в программы расчета дифракционных решеток [14-16], [22], [23], волноводов и фотонных кристаллов [24] введены эквивалентная „Диэлектрическая проницаемость“ $\varepsilon_{e}$ и эквивалентная „толщина“ $t_{e}$ графена. При введении $\varepsilon_{e}, t_{e}$ мы использовали аналогию с тонким диэлектрическим слоем с диэлектрической проницаемостью $\varepsilon$ и толщиной $t$. При решении электродинамических задач этот слой можно заменить бесконечно тонким импедансным слоем, на котором выполняются приближенные граничные условия [25]

$$
\mathbf{j}=i \frac{k(\varepsilon-1) t}{Z_{0}} \mathbf{E}_{t g},
$$

где $Z_{0}$ - волновое сопротивление свободного пространства, $\mathbf{E}_{t g}$ - напряженность тангенциального электрического поля, эквивалентный ток определяется через скачок напряженности магнитного поля при переходе через слой

$$
\mathbf{j}=[\mathbf{u}, \Delta \mathbf{H}] .
$$

Сравнивая (1) с формулой Кубо

$$
\mathbf{j}=\sigma \mathbf{E}_{t g},
$$

получим

$$
\varepsilon_{e}=1-\frac{Z_{0}\left(i \sigma^{\prime}+\sigma^{\prime \prime}\right)}{k t_{e}} .
$$

Параметр $t_{e}$ может быть любой при условии $t_{e} \ll \lambda$, где $\lambda$ - длина волны в вакууме. Это не значит, что графен имеет такую введенную толщину и такую диэлектрическую проницаемость. Это говорит лишь о том, что свойства графена для указанного круга задач можно описать как свойства диэлектрического слоя с введенными параметрами.

Расчеты графеновых структур разными методами расширяют круг решаемых задач электродинамики графеновых структур, позволяет перейти к решению нелинейных задач. Кроме того, расчет устройств двумя независимыми методами подтверждает достоверность теоретических результатов.

\section{2. Результаты моделирования поляризационных эффектов при дифракции $\mathrm{THz}$ волн на метаповерхности из прямоугольных нанолент графена}

При помощи разработанного вычислительного алгоритма методом ФАБ проведено математическое моделирование дифракции $\mathrm{THz}$ волн на метаповерхности из 
$a$

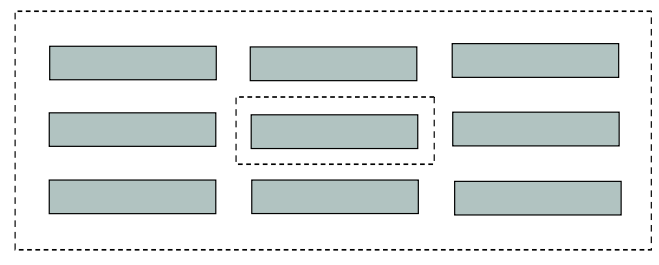

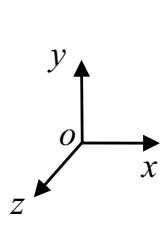

$b$

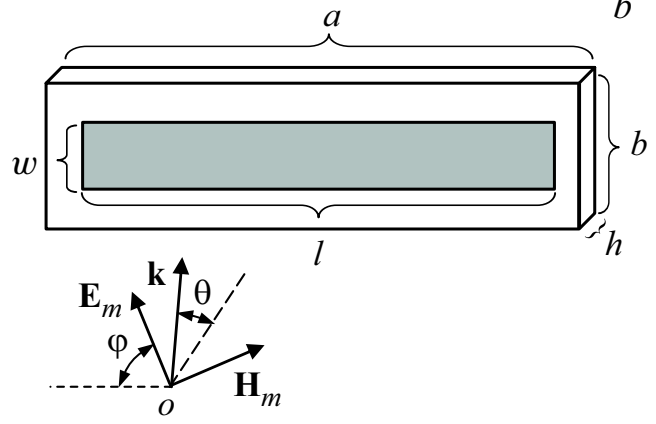

Рис. 1. Расчетная схема дифракции ТЕМ-волны на графеновой метаповерхности: (a) 2D-решетка из прямоугольных нанолент графена; $(b)$ ячейка метаповерхности и ориентация падающей ТЕМ-волны с волновым вектором $\mathbf{k} ; \varphi-$ угол ориентации вектора $\mathbf{E}$ волны к нанолентам графена; $\theta-$ угол падения волны; $a, b-$ периодичность 2D-решетки; $w, l-$ размеры прямоугольной наноленты графена.
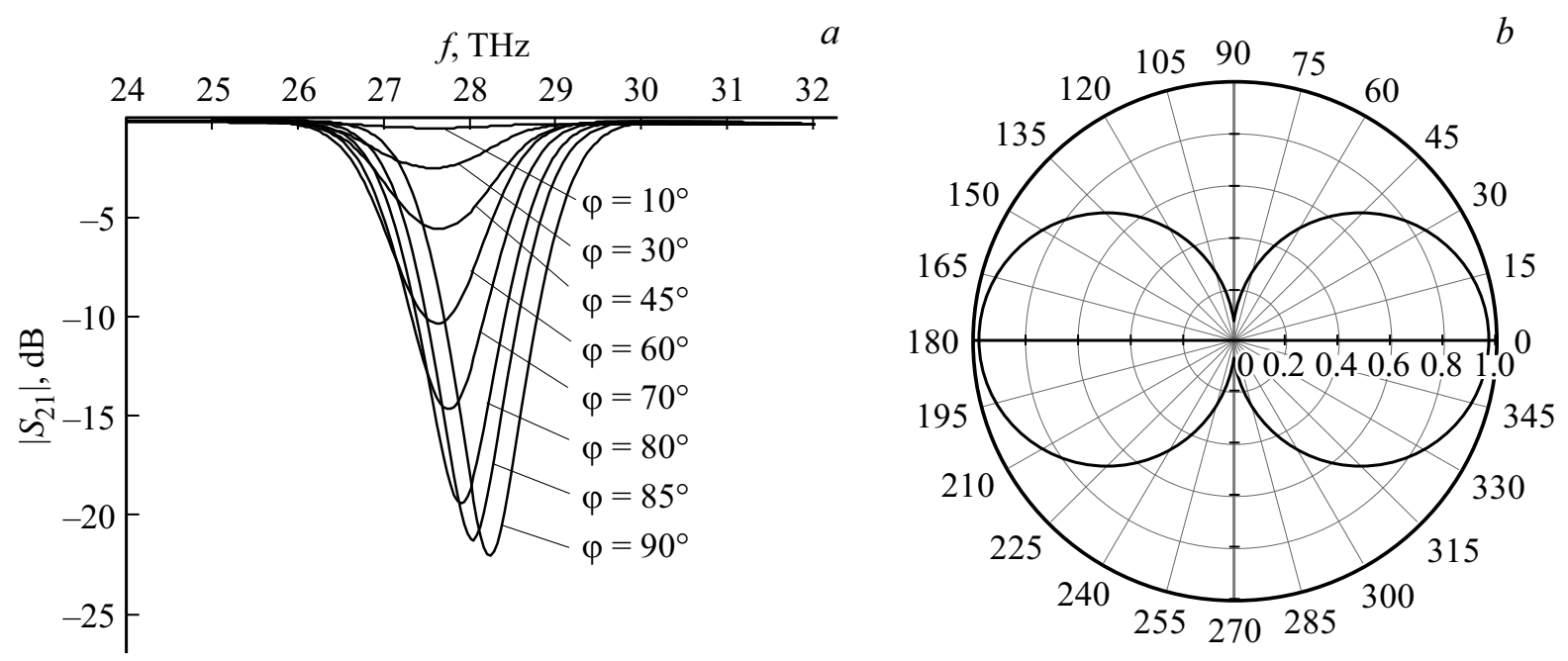

Рис. 2. Зависимость модуля коэффициента прохождения $\left|S_{21}\right|$ ТЕМ-волны через метаповерхность из прямоугольных нанолент графена: $(a)$ от частоты при различных значениях угла $\varphi$ ориентации вектора Е падающей ТЕМ-волны к нанолентам графена; (b) от угла $\varphi$ ориентации вектора $\mathbf{E}$ падающей ТЕМ-волны к нанолентам на частоте $f=28.7 \mathrm{THz}$.

прямоугольных нанолент графена на диэлектрической подложке в $\mathrm{THz}$ диапазоне частот.

Результаты расчета коэффициента прохождения $\left|S_{21}\right|$ ТЕМ-волны через метаповерхность из прямоугольных нанолент графена $(a=2 \mu \mathrm{m}, b=0.2 \mu \mathrm{m}, w=0.1 \mu \mathrm{m}$, $l / a=0.9)$ на подложке из двуокиси кремния $\mathrm{SiO}_{2}$ ( $h=0.5 \mu \mathrm{m}, \varepsilon=2.2$ ) (рис. 1 ) от частоты при различных значениях угла $\varphi$ ориентации вектора $\mathbf{E}$ падающей ТЕМволны к нанолентам графена для значения химического потенциала $\mu_{c}=0.57 \mathrm{eV}$ в диапазоне частот $24-32 \mathrm{THz}$ показаны на рис. 2, $a$.

При изменении угла от $\varphi=0^{\circ}$ (вектор Е ТЕМ-волны параллелен нанолентам графена) до $\varphi=90^{\circ}$ (вектор $\mathbf{E}$ ТЕМ-волны перпендикулярен нанолентам графена) коэффициент прохождения $\left|S_{21}\right|$ существенно уменьшается. При $\varphi=90^{\circ}$ значение коэффициента прохождения $\left|S_{21}\right|$ через структуру близко к единице (наблюдается практически полное прохождение волны через графено- вую метаповерхность). При $\varphi=0^{\circ}$ значение коэффициента прохождения $\left|S_{21}\right|$ минимальное (-22 дБ) на частоте $28.3 \mathrm{THz}$ (при $\mu_{c}=0.57 \mathrm{eV}$ ).

Минимумы коэффициента прохождения $\left|S_{21}\right|$ расположены на характерных частотах, обусловленных плазмонным резонансом фундаментальной моды [26] в графеновых нанолентах конечной длины. При $\varphi=90^{\circ}$ частота плазмонного резонанса (для данных геометрических размерах нанолент графена и периода структуры при значении химического потенциала $\mu_{c}=0.57 \mathrm{eV}$ ) равна $f=28.7 \mathrm{THz}$ (рис. $2, a$ ). При изменении угла $\varphi$ от $0^{\circ}$ до $90^{\circ}$ наблюдается уменьшение значения минимума $\left|S_{21}\right|$ и некоторое смещение его положения в сторону более высоких частот (рис. 2, $a$ ).

Расчетные поляризационные характеристики - зависимости модуля коэффициента прохождения $\left|S_{21}\right|$ ТЕМ-волны через графеновую метаповерхность (рис. 1) от угла $\varphi$ ориентации вектора $\mathbf{E}$ падающей ТЕМ-волны 


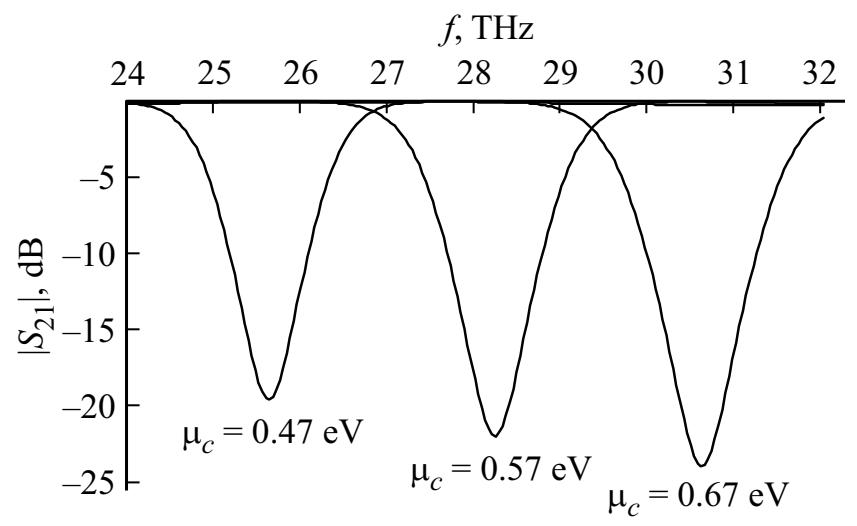

Рис. 3. Частотные зависимости модуля коэффициента прохождения $\left|S_{21}\right|$ ТЕМ-волны через метаповерхность из прямоугольных нанолент графена при изменении химического потенциала $\mu_{c} . \varphi=90^{\circ}$.

к нанолентам графена на частоте $f=28.7 \mathrm{THz}$ для $\mu_{c}=0.57 \mathrm{eV}$ показаны в полярной системе координат на рис. $2, b$.

Результаты расчета - зависимости модуля коэффициента прохождения $\left|S_{21}\right|$ TЕМ-волны через графеновую метаповерхность от частоты при $\varphi=90^{\circ}$ для различных значений химического потенциала $\mu_{c}(0.47-0.67 \mathrm{eV})$ показаны на рис. 3. Параметры и геометрические размеры 2D-решетки и нанолент те же, что и на рис. 2, $b$. При увеличении значения химического потенциала $\mu_{c}$ положение минимума коэффициента прохождения смещается в сторону более высоких частот. Рабочая частота поляризатора, определяемая положением и значением минимума коэффициента прохождения, управляется изменением значения химического потенциала (величиной внешнего постоянного электрического поля) в широком интервале $\mathrm{THz}$ частот и зависит от соотношения геометрических размеров нанолент и решетки.

\section{3. Результаты моделирования $\mathrm{THz}$ поглотителей на основе 2D-решеток из графеновых полосок на многослойных подложках, содержащих графеновые и диэлектрические слои}

Проведено моделирование дифракции двумя методами - методом приближенных граничных условий (ПГУ) и методом ОИУ. На основе проведенного моделирования построены частотные характеристики коэффициентов отражения $R=\left|S_{11}\right|^{2}$, прохождения $T=\left|S_{21}\right|^{2}$ и потерь $P=1-R-T$ при различных изменениях параметров. Результаты расчетов двумя методами совпали, что подтверждает справедливость введения эквивалентной „диэлектрической“ проницаемости графена.

Результаты электродинамического расчета частотных зависимостей параметров поглотителей на основе 2D-решеток из графеновых полосок представлены на рис. 4-8. Расчет проведен при нормальном падении волны $(\theta=0$, рис. $1, b)$, кроме рис. 7 .

Структура семислойного поглотителя (снизу вверх) приведена на рис. 4, $a: 1-$ подложка $n=1.45 ; 2-$ графеновый слой; 3 - диэлектрический слой толщиной $h_{d}$ и показателем преломления $n_{d} ; 4-$ графеновый слой; 5 - такой же диэлектрический слой $h_{d}, n_{d} ; 6-2 \mathrm{~d}-$ решетка из графеновых прямоугольных нанолент; 7 воздух. Там же изображены его характеристики. При увеличении количества графеновых и диэлектрических слоев резонансная частота не меняется, коэффициент поглощения, естественно, растет (рис. 4, $b$ ).
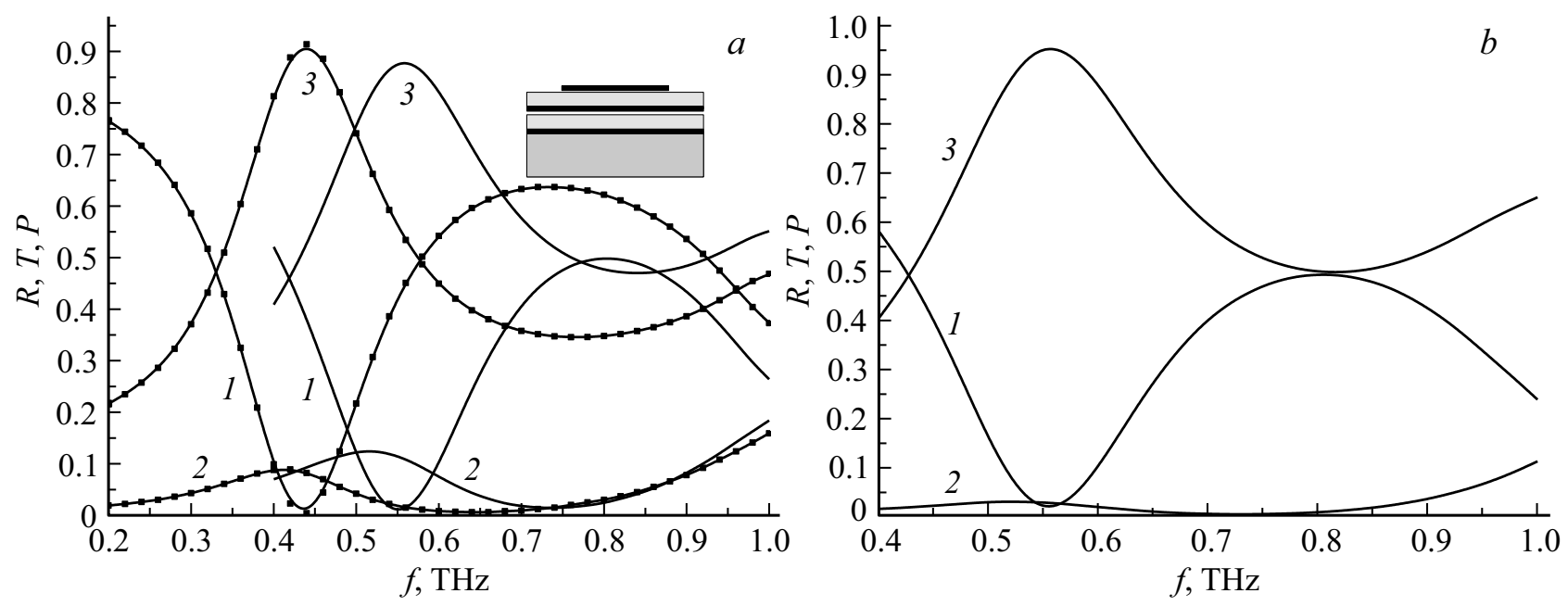

Рис. 4. Характеристики семислойного $(a)$ и девятислойного $(b)$ поглотителя на основе $2 \mathrm{D}-$ решетки из квадратных графеновых полосок при нормальном падении. Кривые $1-R, 2-T, 3-P . a=b=70 \mu \mathrm{m} . h_{d}=25 \mu \mathrm{m}, n_{d}=1.77$. Параметры графена $T=300 \mathrm{~K}, \mu_{c}=0.25 \mathrm{eV}, \tau=1 \mathrm{ps}$. Линии с символами - размеры полосок $w=l=60 \mu \mathrm{m}$, без символов $w=l=50 \mu \mathrm{m}$. 


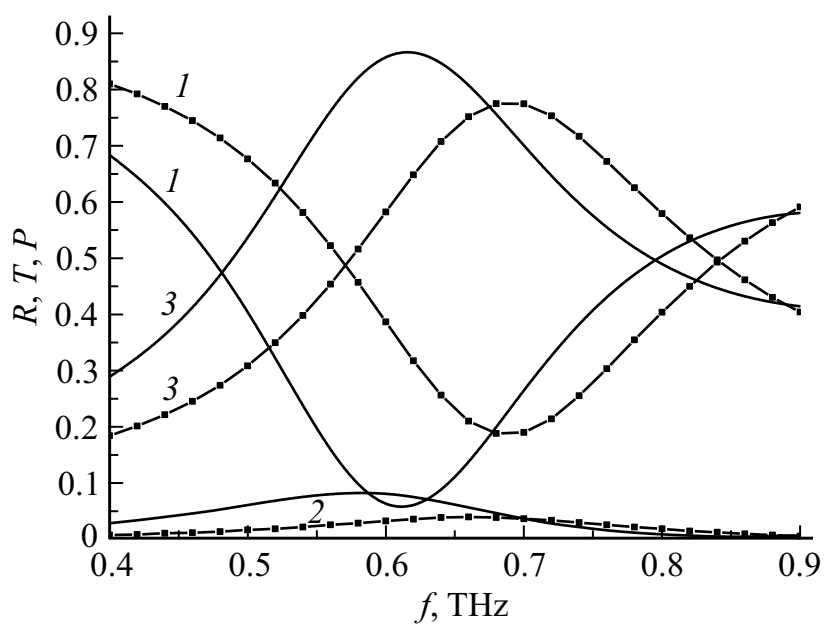

Рис. 5. Характеристики поглотителя на основе 2D-решетки при нормальном падении. $w=l=50 \mu \mathrm{m}$, остальные параметры как на рис. 4. Линии с символами $-\mu_{c}=0.55 \mathrm{eV}$, без символов $\mu_{c}=0.35 \mathrm{eV}$.

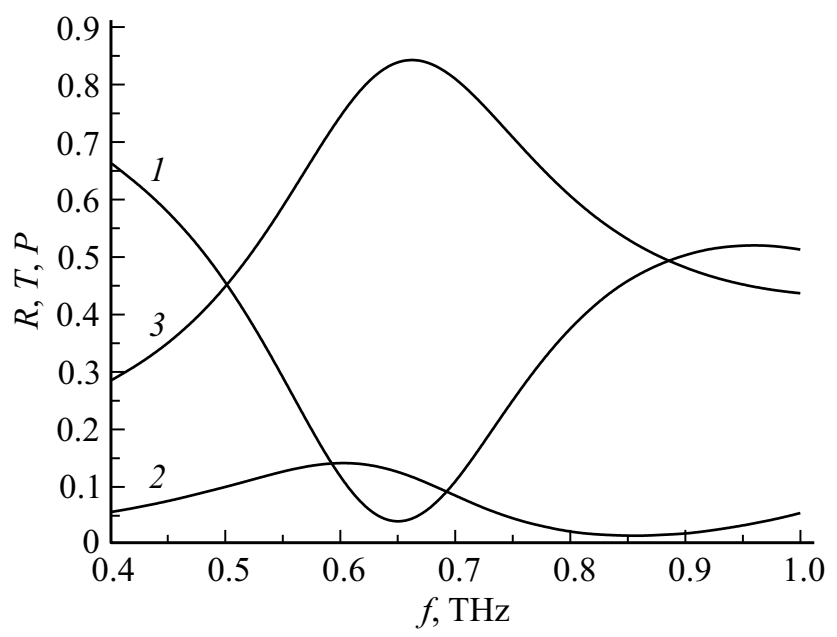

Рис. 6. Характеристики поглотителя на основе 2D-решетки при нормальном падении. $n_{d}=1.45$, остальные параметры как на рис. 4.

Как показывает более детальное моделирование, толщины диэлектрических слоев $h_{d}$ и их показатель преломления $n_{d}$ влияют как на согласование, так и на положение резонанса. Они выбраны из условий минимума коэффициента отражения и максимума потерь. Небольшое изменение $h_{d}$ на $\pm 5 \mu \mathrm{m}$ приводит к изменению резонансной частоты на $\approx \mp 0.3 \mathrm{THz}$.

Максимум поглощения обусловлен резонансом фундаментальной моды поверхностного ППП, распространяющегося в нанолентах графена конечной длины на границе графеновых нанолент с диэлектриком. Поэтому резонансная частота зависит как от размера полосок (рис. 4), так и от параметров графена (рис. 4, 5) и диэлектрика, на котором лежат полоски (рис. 6). С уменьшением показателя преломления диэлектриче- ского слоя $n_{d}$ и увеличением $\mu_{c}$ уменьшается длина волны ППП, поэтому резонансная частота растет (рис. 5,6). Существует оптимальный $\mu_{c}$, при котором наблюдается максимум поглощения.

Длина волны ППП много меныше длины волны в вакууме $\lambda$. Поэтому резонансный размер графеновых полосок порядка $0.1 \lambda$. Толщина диэлектрических слоев

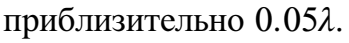

Эффект резонансного поглощения наблюдается в достаточно широком диапазоне углов падения $\theta$. Для примера на рис. 7 приведены характеристики решетки из квадратных графеновых полосок при $\theta=30^{\circ}$. Следует отметить, что эффект наблюдается для обеих поляризаций падающей волны - $\left(p\right.$-поляризация $-H_{\uparrow}=0, s$ поляризация $-E_{\uparrow}=0$, символ „ґ“ означает компоненту

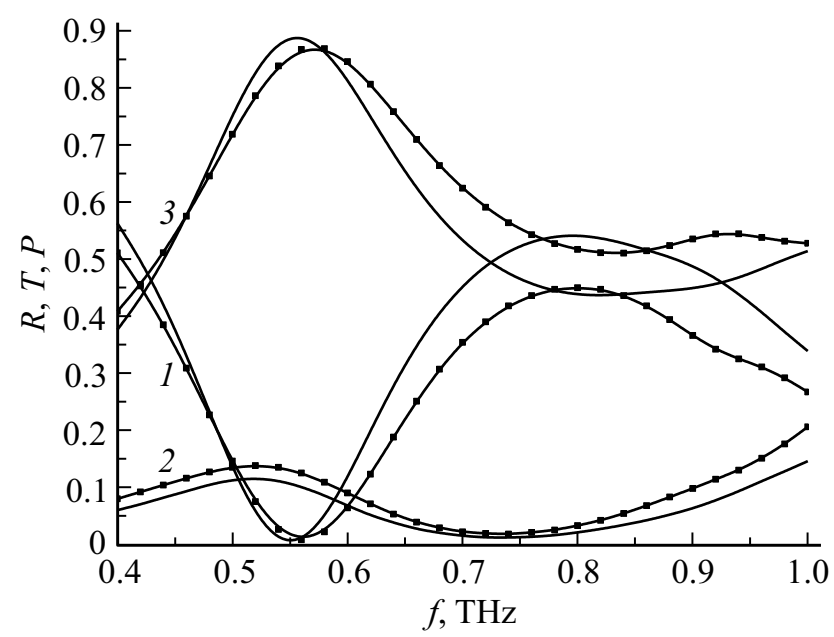

Рис. 7. Характеристики поглотителя на основе 2D-решетки при угле падения $30^{\circ}$, остальные параметры как на рис. 4. Линии с символами - $p$-поляризация, без символов $-s$ поляризация падающей волны.

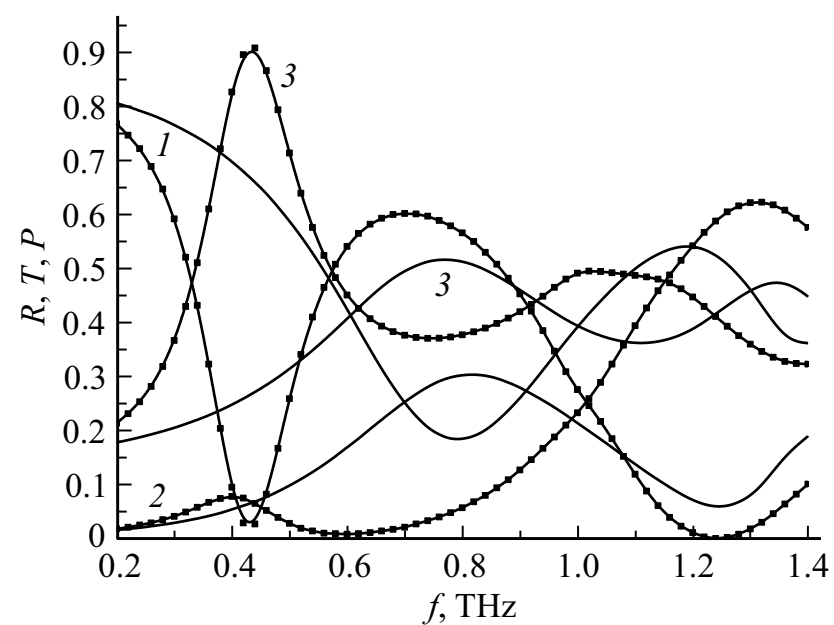

Рис. 8. Характеристики 2D-решетки из прямоугольных графеновых полосок при нормальном падении. $w=60 \mu \mathrm{m}$, $l=20 \mu \mathrm{m}, a=70 \mu \mathrm{m}, b=30 \mu \mathrm{m}$. Остальные параметры как на рис. 5. Обозначения кривых как на рис. 7. 
поля, перпендикулярную плоскости падения). Причем резонансная частота слабо зависит от поляризации.

На рис. 8 представлены результаты расчетов поглотителя из прямоугольных полосок. В случае $p$-поляризации вектор электрического поля падающей волны параллелен широкой стороне нанолент графена $(\varphi=0$ (см. рис. $1, b)$ ). Резонансная частота фундаментальной моды ППП определяется в первую очередь длиной наноленты. Поэтому резонансная частота меньше, а потери больше, чем при падении $s$-поляризованной волны, У которой вектор электрического поля параллелен узкой стороне нанолент $\left(\varphi=90^{\circ}\right.$ (см. рис. $\left.\left.1, b\right)\right)$.

\section{Заключение}

Из результатов математического моделирования следует, что при изменении ориентации вектора электрического поля падающей ТЕМ-волны от параллельной до перпендикулярной нанолентам графена коэффициент прохождения существенно уменьшается, и в полосе непропускания на резонансной $\mathrm{THz}$ частоте метаповерхность из прямоугольных нанолент графена является поляризатором. Изменение значения химического потенциала (действием внешнего электрического поля) является способом эффективного управления характеристиками поляризаторов $\mathrm{THz}$ диапазона на основе нанолент графена конечной длины.

Как показывают результаты моделирования, метаповерхность из квадратных графеновых полосок на многослойной подложке, содержащей графеновые и диэлектрические слои, является эффективным поглотителем в $\mathrm{THz}$ диапазоне частот, который поглощает почти 100\% падающей на нее энергии при резонансе ППП. Рабочая частота $\mathrm{THz}$ поглотителя - резонансная частота ППП - зависит как от размера полосок, так и от параметров графена и диэлектрика. В случае 2D-решетки из квадратных графеновых полосок эффект резонансного поглощения наблюдается в достаточно широком диапазоне углов падения ТЕМ-волны. Возможно управление характеристиками $\mathrm{THz}$ поглотителей как пассивное изменением размеров решетки и диэлектрических слоев, так и активное - изменением значения химического потенциала $\mu_{c}$ (величиной внешнего постоянного электрического поля) в широком интервале $\mathrm{THz}$ частот.

Результаты электродинамического расчета могут быть использованы для создания устройств $\mathrm{THz}$ диапазона на основе метаповерхностей с элементами в виде микро- и нанолент графена конечной длины: быстро перестраиваемых высокоскоростных поляризаторов и поглотителей с управляемой электрическим полем частотой, которые в перспективе будут работать и в ближнем ИК диапазоне.

Работа выполнена в рамках реализации базовой части госзадания, проект 3.5398.2017/8.9.

\section{Список литературы}

[1] Chen P.-Y., Soric J., Padooru Y.R., Bernety H.M., Yakovlev A. et al. // New J. of Physics. 2013. V. 15. P. 123029.

[2] Fallahi J. Perruisseau-Carrier. // Phys. Rev. B. 2012. V. 86. P. 195408.

[3] Zhang Y., Feng Y., Zhu B., Zhao J., Jiang T. // Optics Express. 2014. V. 22. P. 22743.

[4] Чернозатонский Л.А., Сорокин П.Б., Артюх А.А. // Усп. хим. 2014. Т. 83. В. 3. С. 251-279.

[5] Yao G., Ling F., Yue J., Luo C., Ji J., Ya J. // Optics Express. 2016. V. 24. P. 1518.

[6] He X., Yao Y., Zhu Z., Chen M., Zhu L., Yang W., Yang Y., Wu F., Jiang J. // Optical Materials Express. 2018. V. 8. P. 1031.

[7] Xu Z., Wu D., Liu Y., Liu C., Yu Z., Yu L., Ye H. // Nanoscale Res. Lett. 2018. V. 13. P. 143.

[8] Chen D., Yang J., Zhang J., Huang J., Zhang Z. // Scientific Reports. 2017. V. 7. P. 15836.

[9] Huidobro P.A., Maier S.A., Pendry J.B. // EPJ Appl. Metamat. 2017. V. 4. P. 6.

[10] Mou N., Sun S., Dong H., Dong S., He Q., Zhou L., Zhang L. // Optics Express. 2018. V. 26. P. 11728-11736.

[11] Cen C., Chen J., Lin H., Liang C., Huang J., Chen X., Tang Y., Yi Z., $X u X$. arXiv preprint arXiv:1802.10285, 2018.

[12] Chen J., Zeng Y., Xu X., Chen X., Zhou Z., Shi P., Yi Z., Ye X., Xiao S., Yi Y. // Nanomaterials. 2017. V. 8. P. 175.

[13] Cui Y., He Y., Jin Y., Ding F., Yang L., Ye Y., Zhong S., Yinyue Lin Y., He S. // Laser Photonics Rev. 2014. V. 8. N 4. P. 495.

[14] Лерер А.М., Цветянский Е.А. // Письма в ЖТФ. 2012. T. 38. B. 21. C. $77-81$.

[15] Лерер А.М., Иванова И.Н., Клещенков А.Б., Махно В.В., Махно П.В., Тимошенко П.Е. // Физические основы приборостроения. 2016. Т. 5. № 5(22). С. 90-98.

[16] Кайдашев Е.М., Лерер А.М., Головачева Е.В., Кайдашев В.Е, Лянгузов Н.В., Цветянский Е.А. // РЭ. 2017. T. 62. № 12. C. 1173-1181. doi $10.7868 / \mathrm{S} 0033849417110055$.

[17] Hanson G.W. // J. of Appl. Phys. 2008. V. 103. P. 064302.

[18] Никольский В.B. Декомпозиционный подход к задачам электродинамики. М: Наука, 1983. 297 с.

[19] Голованов О.A. // РЭ. 2006. Т. 51. № 12. С. 1423-1430.

[20] Голованов О.А., Макеева Г.С., Ринкевич А.Б. // ЖТФ. 2016. T. 86. B. 2. C. $119-126$.

[21] Лерер А.М., Иванова И.Н. // РЭ. 2016. Т. 61. № 5. C. $435-441$. doi 10.7868/S0033849416050089

[22] Лерер А.М. // РЭ. 2012. Т. 57. № 11. С. 1160-1169.

[23] Кайдашев Е.М., Ллнгузов Н.В., Лерер А.М., Распопова Е.A. // Письма в ЖТФ. 2014. Т. 40. В. 7. С. 79-86.

[24] Lerer A.M., Donets I.V., Kalinchenko G.A., Makhno P.V. // Photon. Res. 2014. V. 2. N 1. P. 31-37. doi org/10.1364/prj.2.000031

[25] Вайнштейн Л.А. Теория дифракции и метод факторизации. М.: Сов. Радио, 1966. 431 с.

[26] Gao W., Shu J., Qiu C., Xu Q. // ACS Nano. 2012. V. 6. N 9. P. 7806 . 